\title{
Late effects after allogeneic hematopoietic cell transplantation with busulphan conditioning in 33 childhood leukemia survivors (1987-2013)
}

\author{
Fernand Freycon ${ }^{1}$, Léonie Casagranda ${ }^{1-3}$, Béatrice Trombert-Paviot ${ }^{3,4}$ and Claire Berger Ber, $^{2,3}$ \\ ${ }^{1}$ Childhood Cancer Registry of the Rhône-Alpes Region, University of Saint-Etienne, Saint-Etienne, France \\ ${ }^{2}$ Department of Pediatric Hematology and Oncology Unit, University Hospital of Saint-Etienne, Saint-Etienne, France \\ ${ }^{3}$ Host Research Team EA4607 SNA-EPIS, PRES Lyon, Jean Monnet University, University Hospital, Saint-Etienne, France \\ ${ }^{4}$ Department of Public Health and Medical Informatics, University of Saint-Etienne, Saint-Etienne, France
}

\begin{abstract}
Late effects (LE) after busulphan (BU) conditioning Hematopoietic Cell Transplantation (HCT) in childhood leukemia survivors are rarely studied. LE were retrospectively collected for 33 childhood leukemia survivors (median age $21 \mathrm{y}$ at follow-up) treated with BU myeloablative conditioning allogeneic HCT. Median delay after HCT was 14.0y and median age at evaluation was 21.0y (17.0-33.5). Patients had a chronic Graft versus Host Disease (cGvHD) ( $\mathrm{n}=3$ ). The mean number of severe late effects was 1.1 per patient: decreased height at adulthood $(n=4)$; Growth Hormone deficit $(n=1)$; risk of impaired fertility ( $n=14 / 18$ females; $n=7 / 15$ males; 2 women had a child); iron overload ( $n=3)$; mellitus diabetes ( $n=1)$; pulmonary LE ( $=2)$; psychiatric disorders ( $n=3)$; sclerodermic cGvHD ( $=1)$; severe academic difficulties $(n=3)$. On the contrary, we found no cardiac, renal or CNS LE, and no secondary cancer.
\end{abstract}

Among the other non-severe LE, there was: alopecia ( $n=3)$; treated hypogonadism ( $n=13$ - all females); low weight ( $n=10)$; minor overweight ( $\mathrm{n}=13)$; hepatic focal nodular hyperplasia $(n=9)$; dental hypoplasia $(n=6)$; osteopenia $(n=4)$; hypertriglyceridemia $(n=4)$; moderate cataract $(n=1)$. Conclusion: The mean number of severe late effects was $1.1( \pm 1.0)$ per patient, significantly less than in our other cohort of 71 children grafted after TBI conditioning published in $2019(2.3 \pm 1.5$; $<<0.0001)$.

\section{Introduction}

After allogeneic hematopoietic cell transplantation (allo-HCT) for childhood leukemia, the pediatrician, and primarily the parents of the cured child, would like to know the number and the severity of the late effects (LE) expected at adulthood. Leiper, with a median delay of 7.9 years after allo-HCT, noted that the mean number of late effects (any grade) increased to 5 in the cohort of patients treated with total body irradiation (TBI) conditioning vs. 2.3 in the cohort of patients treated with busulphan conditioning (BU) [1]. Several publications are available in literature, but the studied cohorts included both patients treated with $\mathrm{BU}$ conditioning and with TBI conditioning, and the conclusions about LE presented mainly the harmful effects of TBI conditioning [2-8]. For example, for Vrooman et al., in multivariate analysis, TBI were predictive of increased risk of cataract, growth deficiency and hypothyroidism [7]. But, LE after BU conditioning are studied separately and in usual medical terms in the study of Bernard et al. [4]. The number of LE (any grade) after BU was 2.35 with an increased risk of overweight $(\mathrm{OR}=3.9)$ and alopecia $(\mathrm{OR}=11.2)$. Bresters et al. confirmed the risk of alopecia in $16 \%$ of patients treated with $\mathrm{BU}[8]$.

The aim of this present work was to precise the number, type and degree of severity of expected late effects at adulthood after BU conditioning HCT, using the usual medical vocabulary, easier to understand for the patient.

\section{Materials and methods}

This retrospective study concerned the long-term follow-up of the cohort of subsequent leukemia patients diagnosed since 1987 before the age of 15 years, in children living in the Rhône-Alpes administrative area in France, who received an allo-HCT with myeloablative conditioning without TBI. Eligibility criteria included a delay of 3 years without relapse after allo-HCT and the age of 17 years at the cutoff date (i.e., 01/02/2017). According to the eligibility criteria, 33 patients were included. It consisted in 20 Acute Myeloid Leukemia (AML), 7 Acute Lymphoblastic Leukemia (ALL), 3 Chronic Myeloid Leukemia (CML), and 3 Myelodysplastic Syndrome (MDS). The HCT conditioning always included busulphan (BU) at a total dose of $16 \mathrm{mg} / \mathrm{kg}$ associated with cyclophosphamide (BUCY) in 21 patients or with cytarabine and melphalan (BAM) in 7 patients or with other drugs in 5 . The HCT type was genoidentical in 21 and MUD (Matched Unrelated Donor) in 12. The allo-HCT was done in first intention in 30 patients, after relapse in 2 , and before the start of puberty in 22 patients and during the puberty period in 11 . Only 3 patients suffered from an active chronic Graft versus Host Disease (cGvHD). The list of the screened LE was that used in our previous publication about LE after TBI but it is not restrictive [9]. Arbitrarily, the LE were classified in 2 categories: either standard or severe - when symptomatic and requiring a significant or binding

${ }^{\star}$ Correspondence to: Léonie Casagranda, Department of Pediatric Hematology and Oncology Unit, University Hospital of Saint-Etienne, 42055 Saint-Etienne Cedex 02, France, Tel: +33 477127 937, E-mail: leonie.casagranda@chu-stetienne.fr

Key words: childhood leukemia, busulphan conditioning, hct, late effects, fecundity Received: April 14, 2020; Accepted: May 08, 2020; Published: May 11, 2020 
treatment. All the observed LE were recorded, except those related to disease prior to leukemia. We considered the LE related to the leukemia treatment. No LE seemed related to a new individualized disease but we included a high blood pressure revealed at 20 years old and a mellitus diabetes treated with insulin. On the contrary, we have excluded from the studied LE the following pathologies: Gall or renal stones, hearing loss or deafness and idiopathic scoliosis.

Concerning academic difficulties, we only considered an educational backwardness of 3 years or more. Indeed, until recently in France, a child had to have acquired the academic knowledge of the previous level to obtain promotion to the next grade level.

\section{Long-term follow-up}

Patients were seen in consultation in the pediatric hematology unit until the age of de 20 years. Thereafter, a follow-up was established combining on one hand the general practitioner when required, and on the other hand a regular annual follow-up by a medical expert (endocrinologist, internist, hematologist...) well informed about the LE to screen. Finally, in 2017-2018, we have systematically contacted the general practitioner or the medical expert to obtain current information about each included patient.

\section{Statistical analysis}

We used Student's test to compare the average number of severe late effects per patient between the patients treated with and without fTBI conditioning. We used chi-square test or Fisher's exact test to compare the different groups of number of severe late effects per patient (i.e., $<2$ LE per patient $v s$. $\geq 2$ LE per patient).

\section{Results}

Tables 1 and 2 show severe and nonsevere late effects in the studied cohort comparing our present results with that of Bernard et al. and with our prior study on LE after TBI.

\section{Severe late effects}

A severe decreased height as final height at adulthood $(<162.5 \mathrm{~cm})$ was noted in $2 / 15$ males and $2 / 18$ females $(<152.0 \mathrm{~cm}$ ) (Table 1$)$. Only one patient presented a Growth Hormone $(\mathrm{GH})$ deficit.

Table 1. Comparison of severe late effects after HCT between the studied cohort (A) and two cohorts in the literature (B) and (C)

\begin{tabular}{|c|c|c|c|c|}
\hline & $\begin{array}{c}\text { Cohort A } \\
\text { Leukemia BU }\end{array}$ & $\begin{array}{c}\text { Cohort B } \\
\text { LEA study BU* }\end{array}$ & $\begin{array}{c}\text { Cohort C } \\
\text { Leukemia fTBI }^{* * *}\end{array}$ & \\
\hline Number of patients (males/females) & $33(15 / 18)$ & $66(40 / 26)$ & $71(35 / 36)$ & \\
\hline Median age at time of HCT (y) (range) & $9.5(0.7-15.1)$ & $6.7(0.5-18.1)$ & $10.5(2.3-18.3)$ & \\
\hline Median age at follow-up (y) (range) & $21.0(17.0-33.5)$ & $19.9(2.1-33.8)$ & $25.0(17.0-42.0)$ & \\
\hline Median delay after HCT (y) (range) & $14.0(4.2-24.4)$ & $11.8(1.0-24.7)$ & $14.8(4.4-27.2)$ & \\
\hline cGvHD & 3 & 12 & 18 & \\
\hline \multicolumn{5}{|l|}{ Severe late effects } \\
\hline Decreased height at adulthood (males $<162.5 \mathrm{~cm}$ ) & 2 & - & 12 & \\
\hline Decreased height at adulthood (females $<152.0 \mathrm{~cm}$ ) & 2 & - & 9 & \\
\hline Growth hormone deficit & 1 & 2 & 15 & \\
\hline Sclerodermic cGvHD & 0 & - & 5 & \\
\hline Osteonecrosis & 0 & 3 & 9 & \\
\hline Risk of infertility in males & 7 & - & 28 & \\
\hline Risk of infertility in females & 14 & - & 25 & \\
\hline Mother- or fatherhood & $2^{\mathrm{a}}$ & 3 & $2^{b}$ & \\
\hline Mellitus diabetes (type I) & 1 & 2 & 8 & \\
\hline Severe pulmonary LE & $2^{\mathrm{c}}$ & - & $5^{\mathrm{d}}$ & \\
\hline Severe renal LE & 0 & - & 5 & \\
\hline High blood pressure & 1 & - & 2 & \\
\hline Severe cardiac LE & 0 & 5 & 2 & \\
\hline CNS LE & 0 & 3 & $1^{\mathrm{g}}$ & \\
\hline Iron overload & 3 & 2 & 6 & \\
\hline Viral transmission & 0 & 3 & 1 & \\
\hline Psychiatric disorders & 3 & - & 11 & \\
\hline Severe academic difficulties & 3 & - & 14 & \\
\hline Second cancer & 0 & $3^{\mathrm{e}}$ & $11^{\mathrm{f}}$ & \\
\hline Other severe LE & 0 & - & 4 & \\
\hline Mean number of LE per patient ( \pm s.d.) & $1.1( \pm 1.0)$ & - & $2.3( \pm 1.5)$ & $\mathrm{P}<0.0001$ \\
\hline Number of patients with $\geq 2$ severe LE & $9(27.3 \%)$ & - & $49(69.0 \%)$ & $\mathrm{P}<0.0001$ \\
\hline
\end{tabular}

Abbreviations: allo-HCT, allogeneic hematopoietic cell transplantation; BU, conditioning regimen based on busulphan; CNS, central nervous system; fTBI, fractionated total body irradiation; cGvHD, chronic graft versus host disease; s.d., standard deviation; LE, late effect

* Bernard F, et al. Health status of childhood leukemia survivors who received hematopoietic cell transplantation after BU or TBI: an LEA study. Bone Marrow Transplant. 2014.

**Freycon F, et al. The impact of severe late effects after 12 Gy fractionated total body irradiation and allogeneic stem cell transplantation for childhood leukemia (1988-2010). Pediatr

Hematol Oncol. 2019.

a two mothers at 22 and 27 years old, no father

b two mothers at 23 and 29 years old - another sterile female had 2 children after oocyte donation - No father but 4 males had a child after sperm donation

c obliterans bronchiolitis (OB)

${ }^{d}$ including 3 with obliterans bronchiolitis

$\mathrm{e}$ including one with thyroid carcinoma

${ }^{\mathrm{f}}$ including 7 with thyroid carcinoma

$\mathrm{g}$ cerebral cavernoma 
Table 2. Comparison of other late effects after HCT between the studied cohort (A) and two cohorts in the literature (B) and (C)

\begin{tabular}{|c|c|c|c|}
\hline & $\begin{array}{c}\text { Cohort A } \\
\text { Leukemia BU }\end{array}$ & $\begin{array}{c}\text { Cohort B } \\
\text { LEA study BU* }\end{array}$ & $\begin{array}{c}\text { Cohort C } \\
\text { Leukemia fTBI** }\end{array}$ \\
\hline Number of patients (males/females) & $33(15 / 18)$ & $66^{\mathrm{a}}(40 / 26)$ & $71(35 / 36)$ \\
\hline Mean number of LE per patient ( \pm s.d.) & $1.1( \pm 1.0)$ & $2.35( \pm 0.2)$ & $2.3( \pm 1.5)$ \\
\hline \multicolumn{4}{|l|}{ Median height at adulthood $(\mathrm{cm})$ (range) } \\
\hline Males & $168(160.3-180.0)$ & $171(157-181)$ & $167(141-170)$ \\
\hline Females & $164.9(148.3-169.0)$ & $163(149-176)$ & $158(139.5-170)$ \\
\hline Median BMI at adulthood $\left(\mathrm{kg} / \mathrm{m}^{2}\right)$ (range) & $21.6(14.3-28.6)$ & $22.3(15.9-39.7)$ & $19.2(14.7-31.4)$ \\
\hline Low weight $\left(\mathrm{BMI}<18.5 \mathrm{~kg} / \mathrm{m}^{2}\right)$ & 10 & 21 & 32 \\
\hline Minor overweight $\left(25.0 \leq \mathrm{BMI} \leq 29.9 \mathrm{~kg} / \mathrm{m}^{2}\right)$ & 12 & 10 & 13 \\
\hline Major overweight $(\mathrm{BMI} \geq 30.0 \mathrm{~kg} / \mathrm{m} 2)$ & 0 & 5 & 0 \\
\hline Hypogonadism under treatment & $13^{\mathrm{b}}$ & 22 & $40^{c}$ \\
\hline Hypothyroidism & 4 & 10 & 23 \\
\hline Alopecia & 3 & 17 & \\
\hline Hepatic NFH & 9 & - & 11 \\
\hline Dental hypoplasia & 6 & - & 20 \\
\hline Osteopenia & 4 & 2 & 16 \\
\hline Hypertriglyceridemia & 4 & $2^{\mathrm{d}}$ & 16 \\
\hline Cataract & 1 & 3 & 31 \\
\hline Exostosis & 0 & - & 11 \\
\hline Others & 2 & 0 & 0 \\
\hline
\end{tabular}

Abbreviations: allo-HCT, allogeneic hematopoietic cell transplantation; BU, conditioning regimen based on busulphan; fTBI, fractionated total body irradiation; NFH, nodular focal hyperplasia

*Bernard F, et al. Health status of childhood leukemia survivors who received hematopoietic cell transplantation after BU or TBI: an LEA study. Bone Marrow Transplant. 2014.

**Freycon F, et al. The impact of severe late effects after $12 \mathrm{~Gy}$ fractionated total body irradiation and allogeneic stem cell transplantation for childhood leukemia (1988-2010). Pediatr Hematol Oncol. 2019.

${ }^{\text {a }}$ including 47 allo-HCTs

b including 13 females

including 32 females and 8 males

${ }^{d}$ metabolic syndrome

A global risk of infertility was noted in $7 / 15$ males, defined by a testicular volume $<10 \mathrm{~mL}$ and/or a level of inhibin $\mathrm{B}<15 \mathrm{ng} / \mathrm{L}$ and/or an azoospermia. None of the 3 males grafted during pubertal period gave an available semen sample for storage in a sperm bank. None of the males had a child at a median age at follow-up of 22.1 years. A global infertility risk existed in 14/18 females, defined by a Follicle Stimulating Hormone (FSH) level $>40$ IU/L and/or an Anti-Müllerian Hormone $(\mathrm{AMH})$ level $<3 \mathrm{pMol} / \mathrm{L}$ at a median age at follow-up of 22.2 years. Two women had a child, respectively at the age of 22.2 and 27.3. One woman had an induced abortion at the age of 20 . Another woman had an endometriosis. Only one female had ovarian tissue conservation before allograft.

Mellitus Diabetes requiring insulin treatment was noted in only one patient 3 years after allo-HCT.

Two patients suffered from an obstructive pulmonary disease (bronchiolitis obliterans) late effect related to cGvHD but with favorable evolution.

One patient presented a high blood pressure.

Three patients with iron overload disorders (9\%) with a ferritin level at respectively 1600, 2614 and 1920ng/ml required bleeding or iron chelation. more.

Three females (9\%) had educational backwardness of 3 years or

A depression at adulthood was noted in 2 females and anorexia nervosa in another one.

On the contrary, we observed no osteonecrosis, no sclerodermic Graft versus Host Disease (GvHD), no infection by hepatitis C or B virus, and above all no secondary cancer with a median delay of 14 years after allo-HCT.

The number of severe late effects was 1.1 per patient $( \pm 1.0)(0.8$ in males, 1.3 in females) without any correlation with the delay from alloHCT. Less than one-third of the patients (27\%) had at least 2 severe late effects and only $6 \%$ of the patients had 3 or more severe late effects.

\section{Other late effects}

The final height at adulthood seemed not significantly decreased with a median of $164.9 \mathrm{~cm}(148-169 \mathrm{~cm})$ in females and $168.0 \mathrm{~cm}$ in males (160-180) (Table 2). The measure of the BMI studied between 17 and 22 years old showed a low weight in 10 patients, and a minor overweight in 12 patients (Table 2).

Hypogonadism required a treatment in 13 patients, all females but no male.

Four patients suffered from hypothyroidism. The screening by annual thyroid echography of a thyroid micronodule with a diameter $>8 \mathrm{~mm}$ was positive only in $2 / 18$ patients, always with benign cytology.

Three patients presented a permanent diffuse partial alopecia.

Liver focal nodular hyperplasia was noted in 9 patients.

Concerning dental late effects, 6 patients with radicular hypoplasia or agenesis were noted.

We rarely noted the other LE: Hypertriglyceridemia $(n=4)$, osteopenia $(n=4)$, ophthalmologic LE $(n=2$ including 1 moderate cataract and one amblyopia with an visual acuity of $3 / 10$ and $6 / 10$, complication of a retinal hemorrhage during leukemia treatment), exostosis $(n=0)$. 


\section{Discussion}

We found a mean number of severe late effects of 1.1 per patient without any correlation with delay from allo-HCT, less than one third of the patients had at least 2 severe late effects and only $6 \%$ had 3 or more severe LE. In our other cohort of 71 allo-HCT with fTBI conditioning leukemic children, the mean of severe LE per patient was $2.3(\mathrm{P}<0.0001)$ and nearly three quarters $(69 \%)$ of patients had at least 2 severe $\operatorname{LE}(\mathrm{P}<0.0001)$ [9].

Our results are close to that of Bernard et al. who noted among 66 patients with BU conditioning (including 47 allo-HCT leukemic children) a mean of $2.35 \mathrm{LE}$ (any grade) with an increased risk of overweight $(n=20)$ and alopecia $(n=10)$ [4]. Bresters noted $16 \%$ of diffuse alopecia after BU conditioning [8]. We confirmed the frequency of infertility: only 2 women among 18 gave spontaneously birth to an alive child at 22.2 and 27.3 years old, i.e. younger than in the French general population [10]. None of the 15 males became a father with a median age at follow-up of the cohort of 21 years. Bernard noted that $3 / 66$ patients became a father or a mother. But, it seems to us that infertility after BU conditioning is less severe than after TBI, where we noted only $2 / 71$ patients who became parent, both women [9]. In the cohort of patients treated by allograft with $\mathrm{BU}$ conditioning published by Sanders et al. including 73 females between 14 and 57 of age at the time of allograft and 46 males between 13 and 56 of age, Sanders noted that $0 / 73$ females became pregnant with a follow-up delay since the allograft of 16 years, but $3 / 46$ partners of the men became pregnant with a follow-up delay since allograft from 1 to 5 years including one patient using cryopreserved sperm [11]. Borgmann-Staudt studied infertility in 344 patients treated with HCT for childhood leukemia or severe aplastic anemia (SAA) after BU (196 patients) or TBI (148 patients) at the median age at follow-up of 19 years (range, 12-35): 2 men became father, both treated for a SAA after cyclophosphamide, 3 women (1 SAA, 1MDS, 1 Ewing tumor) after chemotherapy conditioning (1 with busulphan-melphalan; 1 with cyclophosphamide only; 1 with thiothepafludarabine) [12]. Vatanen et al., among 92 females treated with HSCT in childhood with mean age at last visit of 22 years \pm 6.3 (range, 9-41) noted that 5 of the 71 patients treated with fTBI conditioning became mother (4ALL and 1 severe combined immunodeficiency) and 3/10 patients with BU conditioning (1 familial hematophagocytic lymphohistiosis, 1 thalassemia, 1 Morbus Gaucher) [13]. For Rahal et al., fertility seemed better after BU conditioning HCT for thalassemia in childhood (probably because the lack of chemotherapy before the graft). Indeed, with a median age at follow-up of 20.0 years (range, 14.728.3), Rahal and Galambrun noted that among 27 females aged more than 20 years at follow-up, 9 became mother and $4 / 21$ males became father [14].

We noted no second cancer after a median delay after HCT of 14 years but Bernard noted 3 second cancers including 1 thyroid carcinoma with a median delay of 10.2 years when we observed 14 second cancers (including 7 thyroid carcinomas) in 11 patients with a median delay after HCT of 14.8 years [4]. Majhail, among 4318 patients without TBI HCT for LAM and CML including 769 patients grafted before the age of 20 years noted 66 solid cancers at a median of 6 years after HCT. In comparison to general population incidence rate, HCT recipients had $1.4 \mathrm{x}$ higher than expected rate of invasive solid cancers [15].

The main limit of our work was that we didn't use the international Common Terminology Criteria for Adverse Events for LE [16]. For example, as we are concerned, the notion of mellitus diabetes requiring a treatment with insulin is easier to understand for the patient and his medical practitioner than a "metabolic LE grade III". The second limit is not to have included in the severe LE the following pathologies: hypogonadism and hypothyroidism. The strength of our study lays in the fact that we observed LE in one of the rare cohorts, except that of Bernard that included only patients treated with BU HCT for childhood leukemia, with a modest number of 33 patients but a correct median age at follow-up at 21 years (range, 17.0-33.5) [4]. The desirable and urgent future would be the reactivation of the already published cohorts to specify, with a greater follow-up, the spontaneous fertility rate and the rarity of the second cancers.

\section{Acknowledgements}

The authors thank Pr Yves Bertrand, Dominique Plantaz, Mauricette Michallet, Jean-Louis Stephan, Pascal Cathebras, Christine Broussolles, Arnaud Hot, Olivier Chabre, Isabelle Durieu, Hervé Lejeune, and Dr Cécile Renard, Claire Freycon, Pascale Berlier, Aude Brac de la Perriere, Isabelle Guichard, Yadh Khalfallah, Helène Labussiere-Walett, Sylvie Pradines, Sylvie Villard-Fimbel, and Odile Richard. We also thank the numerous general practitioners of the Rhone-Alpes region who actively participated in this long-term follow-up, Audrey Loubier for administrative help and Fina Liu for editorial assistance.

\section{Authors' contributions}

All authors contributed to the manuscript in significant ways and reviewed and agreed upon the manuscript content.

\section{Funding}

No funding supported this work.

\section{Ethics committee approval}

Appropriate ethical approval was obtained for the study. The authors confirm that this paper has not been published previously, is not under consideration for publication elsewhere, and that if accepted will not be published elsewhere in the same form, in English or in any other language, without the written consent of the publisher.

\section{Declaration of interest statement}

The authors declare no conflicts of interest.

\section{References}

1. Leiper $\mathrm{AD}$ (2002) Non-endocrine late complications of bone marrow transplantation in childhood: part II. Br J Haematol 118(1): 23-43.

2. Perkins JL, Kunin-Batson AS, Youngren NM, Ness KK, Ulrich KJ, Hansen MJ, et al (2007) Long-term follow-up of children who underwent hematopoeitic cell transplant (HCT) for AML or ALL at less than 3 years of age. Pediatr Blood Cancer 49(7): 958963. [Crossref]

3. Armenian SH, Sun CL, Kawashima T (2011) Long-term health-related outcomes in survivors of childhood cancer treated with HSCT versus conventional therapy: a report from the Bone Marrow Transplant Survivor Study (BMTSS) and Childhood Cancer Survivor Study (CCSS). Blood 118(5): 1413-1420. [Crossref]

4. Bernard F, Auquier P, Herrmann I (2014) Health status of childhood leukemia survivors who received hematopoietic cell transplantation after BU or TBI: an LEA study. Bone Marrow Transplant 49(5): 709-716.

5. Visentin S, Auquier P, Bertrand Y (2016) The Impact of Donor Type on LongTerm Health Status and Quality of Life after Allogeneic Hematopoietic Stem Cell Transplantation for Childhood Acute Leukemia: A Leucémie de l'Enfant et de L'Adolescent Study. Biol Blood Marrow Transplant 22(11): 2003-2010. [Crossref]

6. Bresters D, Lawitschka A, Cugno C (2016) Incidence and severity of crucial late effects after allogeneic HSCT for malignancy under the age of 3 years: TBI is what really matters. Bone Marrow Transplant 51(11): 1482-1489. 
7. Vrooman LM, Millard HR, Brazauskas R (2017) Survival and Late Effects after Allogeneic Hematopoietic Cell Transplantation for Hematologic Malignancy at Less than Three Years of Age. Biol Blood Marrow Transplant 23(8): 1327-1334. [Crossref]

8. Bresters D, Wanders DCM, Louwerens M (2017) Permanent diffuse alopecia after haematopoietic stem cell transplantation in childhood. Bone Marrow Transplant 52(7): 984-988. [Crossref]

9. Freycon F, Casagranda L, Trombert-Paviot B (2019) The impact of severe late-effects after 12Gy fractionated total body irradiation and allogeneic stem cell transplantation for childhood leukemia (1988-2010). Pediatr Hematol Oncol 36(2): 86-102. [Crossref]

10. Freycon F, Trombert-Paviot B, Casagranda L, Childhood Cancer Registry of the Rhône- Alpes Region Group (2015) Age at birth of first child and fecundity of women survivors of childhood acute lymphoblastic leukemia (1987-2007): A Study of the Childhood Cancer Registry of the Rhône-Alpes Region in France (ARCERRA). Pediatr Hematol Oncol 32(4): 273-283. [Crossref]

11. Sanders JE, Hawley J, Levy W (1996) Pregnancies following high-dose cyclophosphamide with or without high-dose busulfan or total-body irradiation and bone marrow transplantation. Blood 87(7): 3045-3052. [Crossref]
12. Borgmann-Staudt A, Rendtorff R, Reinmuth S (2012) Fertility after allogeneic haematopoi- etic stem cell transplantation in childhood and adolescence. Bone Marrow Transplant 47(2): 271-276.

13. Vatanen A, Wilhelmsson M, Borgström B (2013) Ovarian function after allogeneic hematopoietic stem cell transplantation in childhood and adolescence. Eur J Endocrinol 170(2): 211-218. [Crossref]

14. Rahal I, Galambrun C, Bertrand Y (2018) Late effects after hematopoietic stem cell transplantation for $\beta$-thalassemia major: the French national experience. Haematologica 103(7): 1143-1149. [Crossref]

15. Majhail NS, Brazauskas R, Rizzo JD (2011) Secondary solid cancers after allogeneic hematopoietic cell transplantation using busulfan-cyclophosphamide conditioning. Blood 117(1): 316-322. [Crossref]

16. Common Terminology Criteria for Adverse Events (CTCAE) Version 4.0. Published May 28, 2009 (v4.03: June 14, 2010) U.S.DEPARTMENT OF HEALTH AND HUMAN SERVICES. National Institutes of Health. National Cancer Institute. https:// www.eortc.be/services/doc/ctc/CTCAE_4.03_2010-06-14_QuickReference_5x7.pdf. Accessed February 10, 2020.

Copyright: $\odot 2020$ Freycon F. This is an open-access article distributed under the terms of the Creative Commons Attribution License, which permits unrestricted use, distribution, and reproduction in any medium, provided the original author and source are credited. 